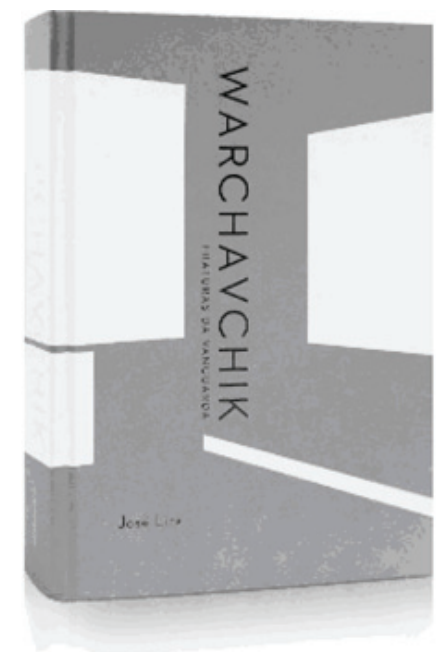

\section{WARCHAVCHIK:}

FRATURAS DA VANGUARDA

LiRA, José Tavares Correia de. São Paulo:

CosaC \& NaIfy, 2OII, 552 P.

ISBN: $978-85-7503-963-2$

\title{
Fernanda Fernandes
}

\section{Gregory WARChAVCHIK, UM VIAJANTE NA História}

O livro de José Lira, Warchavchik: Fraturas da vanguarda, reserva-nos gratas surpresas. Partindo da trajetória do arquiteto, Lira consegue subverter a construção historiográfica linear que, usualmente, rege os trabalhos monográficos ao seccionar o percurso do arquiteto inserindo, em cada uma das etapas cronológicas organizadoras da narrativa, temáticas proeminentes no campo arquitetônico. Valendo-se dessa construção, oferece-nos um texto saboroso, em que arquiteto e arquitetura convivem com situações históricas, culturais e sociais, permitindo ao leitor vislumbrar o universo de possibilidades próprias de cada período e as escolhas individuais feitas em seu interior. Resulta daí uma análise reflexiva e alargada, que não se furta à complexidade própria da arquitetura.

Como toda boa história, também essa tem início com um nascimento. Warchavchik nasce em 1896 em Odessa, principal porto russo ao sul do Império. A identificação de um porto, logo nas primeiras linhas, anuncia a viagem a ser empreendida pelo jovem protagonista, tendo como destino a cidade de Roma dos anos 20, onde irá completar sua formação. Em 1923 transfere-se para São Paulo e, dois anos depois, naturaliza-se brasileiro, constitui família e desenvolve sua obra.

Em Odessa, encontramos um Warchavchik ainda de perfil esfumado, devido aos poucos vestígios documentais que puderam ser resgatados por José Lira em sua cuidadosa pesquisa. Poucos, porém preciosos, oferecem indícios de sua aproximação com a arquitetura nos estudos realizados na Escola de Arte de Odessa. E, além disso, permitem mergulhar no ambiente cultural da cidade que, já na década de 1910, insere-se nos circuitos de vanguarda europeus, acionada 
pela presença de museus, universidades, teatros e bibliotecas. Embora não se possa afirmar em qual medida esse ambiente cultural incidiu na formação do jovem Warchavchik, Lira ensaia várias possibilidades, dividindo com o leitor suas hipóteses na busca de esclarecimento em meio a achados e dúvidas. Portanto, não se trata de buscar origens reveladoras, mas de estabelecer um percurso da experiência vivida, seguindo-Ihe os rastros, por mais sutis que sejam os registros recuperados.

O início em Odessa soaria natural não fosse pelo fato de o arquiteto ucraniano ter sido considerado italiano pela historiografia brasileira desde o texto seminal de Anita Salmoni e Emma Debenedetti, em mecanismo que sobrepõe sua formação à sua origem e, por esse viés, evidenciando o classicismo de matriz italiana presente nas obras por ele produzidas em São Paulo. Essa leitura não é questionada pelo autor, porém relativizada, na medida em que propõe ter sido em São Paulo que Warchavchik efetivamente tomou contato com as vanguardas artísticas e produziu sua arquitetura de matriz moderna. Essa inflexão possibilita uma visada mais livre e exploratória sobre a atuação do arquiteto no Brasil.

Durante sua estadia italiana, que se inicia em 1918, quando se inscreve no Instituto Superior de Belas Artes de Roma, os debates sobre a vanguarda arquitetônica ainda estavam em fermentação no ambiente italiano. Nesse cenário, Lira se apóia na figura de Piacentini, em cujo escritório o jovem profissional trabalhou durante um ano, para explorar o espectro de relações da arquitetura italiana com as propostas centro-europeias e as experiências de Viena, assinalando a multiplicidade de tendências que inferia sobre a produção local.

A chegada do arquiteto a São Paulo como contratado da Cia. Construtora de Santos, de Roberto Simonsen, é uma boa oportunidade para que o autor destaque o pioneirismo da empresa na organização racional do trabalho e a preocupação de contar, em seus quadros, com técnicos especializados. Também é ocasião para que aproxime a experiência brasileira daquelas europeias, evocando a liderança do empresário alemão Walther Rathenau no processo de modernização ligado à indústria, assim introduzindo uma das questões proeminentes do debate centro-europeu em relação à arquitetura moderna. 0 assunto é retomado a partir da análise detalhada de textos do arquiteto publicados na imprensa, estratégia que o destitui do incômodo lugar de autor de um único manifesto, apresentando sua veia polemista de divulgador do avanço dos debates promovidos pelo Congresso Internacional da Arquitetura Moderna (Ciam), além de sinalizar a articulação internacional da arquitetura moderna. De fato, como delegado do Brasil no Ciam a partir de 1930, Warchavchik estreita os laços com as propostas da nova objetividade alemã, hegemônica nos congressos de 1929 e 1930, com os temas da habitação mínima e da construção racional.

Contudo, é significativo observar que o ano de 1927, em que Warchavchik divulga na imprensa a Exposição de Stuttgard, quando é selada a aliança entre arquitetos e industriais nas propostas de moradias racionais, também marca a abertura de seu escritório. No volante de divulgação do escritório, o arquiteto apresenta como referência e validação de sua capacidade profissional a 
experiência adquirida junto de Marcello Piacentini, representante de um moderno classicizante e pouco afeito às inovações espaciais e de linguagem propostas pelas vanguardas europeias. Essa dualidade fica registrada no projeto da Casa da rua Santa Cruz, carta de apresentação de sua adesão ao moderno. Nessa obra, a hesitação entre o conhecido representado por Piacentini e as propostas arquitetônicas modernas fica explicitado na forçada simetria da fachada, que burla a composição espacial de seu interior.

Vale acompanhar a análise das casas realizadas posteriormente, quando Lira se apóia em material iconográfico de qualidade para desvelar o paulatino processo de apropriação das premissas modernas no fazer do arquiteto. Assim, sucedem-se a Casa Modernista da rua Itápolis, a Residência Max Graf, a residência da rua Avanhandava, a Residência Luís da Silva Prado, alinhavadas por um fio condutor que identifica as soluções recorrentes em volumes elementares, que, posteriormente, deslocam-se, a adoção de terraços-jardim e a abertura paulatina das fachadas para o exterior, através de planos envidraçados, tudo balizado pelas dificuldades construtivas enfrentadas para viabilizar tais inovações. Contudo, o excesso de referências mobilizadas para a compreensão dos projetos talvez mais dificultem do que esclareçam as propostas do arquiteto, embora indiquem sua familiaridade com os desenvolvimentos das vanguardas arquitetônicas.

A posição proeminente alcançada pelo arquiteto estrangeiro em sua até então curta estadia no País, atuando como polemista, autor de obra inovadora e interlocutor do Ciam, é uma guinada significativa quando comparada à sua anônima participação nos escritórios italianos. Tal posição impulsiona sua ida ao Rio de Janeiro e o convívio com Lúcio Costa, que nesse momento inicia o processo de mobilização dos arquitetos cariocas para o endosso das premissas modernas. A atuação posterior de Warchavchik em São Paulo revela o profissional envolvido com os negócios familiares, que usa sua competência profissional para viabilizar empreendimentos imobiliários representados por conjuntos de residências de aluguel.

O período de reclusão, identificado por Lira no retorno do Rio de Janeiro para as lides familiares, funciona como pausa para a abordagem do arquiteto já inserido no ambiente cultural paulista, não mais como propagador do novo, mas como participante dos meandros da profissão, das possibilidades de trabalho e das flutuações do gosto de uma clientela abastada. Alguns projetos realizados nos anos 40 talvez merecessem maior atenção, por possibilitarem um diálogo com as novas frentes que se colocam no ambiente arquitetônico paulista, como a chegada de outros profissionais estrangeiros, as transformações urbanas do período, a presença de Le Corbusier no Brasil em 1936 e a posterior consolidação do grupo carioca como significativo núcleo de interlocução nas propostas arquitetônicas modernas.

Nesse sentido, vale ressaltar a solução peculiar da residência de Salomão Klabin, premiada pela prefeitura de São Paulo em 1941 como melhor projeto residencial. Na volumetria definida do bloco principal ressoa a experiência anterior do arquiteto, mas exibindo agora, sem reservas, o telhado de quatro águas. O bloco se articula a outros secundários através de uma colunata, de modo a conformar um pátio, um fechamento do lote. O resultado evoca a 
tipologia das casas com pátio introduzidas na cidade nos anos seguintes pelos arquitetos, também estrangeiros, Rudofsky e Calabi, próximos ao círculo de relações de Warchavchik.

No mesmo período, os projetos de concurso para o Paço Municipal e praça da República, realizados com a participação de Vilanova Artigas, introduzem um problema urbano até então distante das preocupações do arquiteto, mas rotineiros para engenheiros da Politécnica como Artigas, que se formara na escola em 1937. Essa seria ocasião interessante para refletir sobre o encontro de duas gerações, por intermédio de dois protagonistas da arquitetura realizada em São Paulo em momentos distintos e também para evidenciar a arquitetura e o urbanismo como duas frentes de atuação de forte presença no ambiente profissional paulistano.

Ao findar da década de 1940, Lira nos apresenta Warchavchik envolvido com o projeto do Clube Atlético Paulistano, criado em parceria com Zenon Lotufo, Abelardo de Souza, Hélio Duarte e Telesforo Cristofani, os três primeiros com reconhecida filiação ao grupo carioca. No projeto, a aproximação com os postulados de Le Corbusier fica explícita na adoção de pilotes que, ao elevarem do solo a nítida solidez do volume principal, provocam estranhamento, acusando a pouca familiaridade de Warchavchik com esse tipo de solução. Até então, o arquiteto conduzira sua obra na geometria precisa do volume fincado no solo, indicando sua filiação às tendências construtivas centro-europeias. A adesão às soluções com pilotis tem continuidade nas casas de praia feitas no Guarujá, onde a horizontalidade produz resultados interessantes, enfatizados pela continuidade das janelas corridas, que promovem a permeabilidade da arquitetura à natureza, em uma apropriação diferenciada das diretrizes corbusianas.

A ocupação da orla marítima como espaço de lazer serve de contraponto ao congestionamento urbano e ao processo de verticalização das áreas centrais de São Paulo, que, no início da década de 1950, já tem porte de metrópole. Warchavchik participa do processo produzindo seu arranha-céu, mito e paradigma do moderno. O projeto do Edifício Moreira Salles, na avenida São Luiz, é inserido por Lira no interior do processo de especulação imobiliário sofrido pelo centro da cidade, quando os profissionais se organizam em construtoras para enfrentar a competitividade do mercado que constrói a cidade vertical. Em 1952 é criada a construtora Warchavchik-Neumann, responsável por conjuntos de casas e apartamentos.

Além de oferecer um perfil expandido de nosso protagonista, a trajetória proposta por Lira esclarece os meandros da produção arquitetônica, da organização profissional e da cultura de uma época. Mostra que a história da arquitetura não se faz apenas de grandes obras e arquitetos exponenciais. Além disso, revela, nas entrelinhas, o trabalho do historiador que, a partir de pesquisa paciente, tece elaboradas interpretações. Nesse sentido, a apresentação de Adrian Gorelik fornece uma chave precisa de leitura, ao observar que " $O$ trabalho biográfico não é como montar um quebra-cabeça, no qual todas as peças se encaixam criando a ilusão de unidade e destino". De fato, os jogos de paciência têm sido usados como metáfora do trabalho do pesquisador. A citação de Carlo Ginsburg, que abre o texto de Manfredo Tafuri - O projeto histórico 
adverte sobre o risco a que está sujeito o historiador ao buscar, como resultado de sua investigação, uma figura única e definitiva, mesmo porque ele não tem todas as peças disponíveis, como acontece nos jogos de montar. A partir desse mote, Tafuri desenvolve sua reflexão sobre o trabalho do historiador de arquitetura como análise produtora de significados, construção realizada no embate constante entre o historiador e seus objetos.

Os estudos de historiografia conduzidos pelo professor José Lira nos últimos anos, sem dúvida dialogam com essa obra, oferecendo um consistente resultado e avançando problemas e métodos da construção historiográfica. Deixo ao leitor o convite para participar do jogo de multiplicações presente nessa trajetória e aderir à viagem proposta pelo autor, evitando o caminho tranquilizador das ruas de mão única.

Fernanda Fernandes

Professora do Departamento de História da Arquitetura e Estética do Projeto da FAUUSP

feufernandes@terra.com.br 